\title{
ANÁLISE EPISTEMOLÓGICA DAS ESTATÍSTICAS DO ENSINO DE $2 \circ$ GRAU NAS MENSAGENS PRESIDENCIAIS AO CONGRESSO NACIONAL (1971-1979)
}

\author{
Nara Lidiana Silva Dias Carlos*; Ilane Ferreira Cavalcante; Olívia Morais de Medeiros Neta \\ E-mail*: naralid@yahoo.com.br \\ Universidade Federal do Rio Grande do Norte
}

DOI: 10.15628/rbept.2020.10801

Artigo submetido em: jul/2020 e aceito em: nov/2020

\begin{abstract}
RESUMO
O estudo aqui apresentado guarda relação com a temática estatística e educação e está circunscrito no campo da história da educação profissional, pois se situa no contexto da Lei no 5.692/1971, que transformou em profissional o ensino secundário no Brasil. Este estudo tem como objetivo fazer análise do referencial epistemológico, teórico e metodológico nas fontes nominadas Mensagens Presidenciais ao Congresso Nacional, refletindo sobre as estatísticas do ensino de $2^{\circ}$ grau no Brasil. A intenção é demonstrar a utilização de um discurso em que os números tratados de maneira naturalizada servem como manutenção da ferramenta de manipulação social. A metodologia utilizada foi a revisão bibliográfica e análise documental. Para compreender o objeto de estudo, questionamos: Qual a relação entre a epistemologia e as estatísticas educacionais? Como as estatísticas do ensino de $2^{\circ}$ grau são apresentadas nas Mensagens Presidenciais ao Congresso Nacional. $\mathrm{Na}$ intenção de compreendermos esses aspectos, fazemos uso de conceitos como obstáculo epistemológico de Gaston Bachelard (1996), História política de René Rémond (2003), História Serial de Pierre Chaunu (1976) e José D'Assunção Barros (2004). Também refletimos acerca da construção da história da ciência numa perspectiva histórica e sobre relações de poder, baseadas em autores como Michel Foucault (2002), Thomas Kuhn (1987) e Gaston Bachelard (1996). Os resultados obtidos demonstram que o uso das estatísticas educacionais se apresenta, nas fontes estudadas, de maneira que o leitor não questione as informações, mesmo que divirjam ou demonstrem dados que fujam da realidade, pois existe um discurso que dificulta essas indagações.
\end{abstract}

Palavras-chave: Estatísticas educacionais. Ensino de $2^{\circ}$ grau. Fundamentação epistemológica. Mensagens Presidenciais ao Congresso Nacional.

\section{EPISTEMOLOGICAL ANALYSIS OF SECONDARY EDUCATION STATISTICS IN PRESIDENTIAL MESSAGES TO THE NATIONAL CONGRESS (1971-1979)}

\begin{abstract}
The study presented here relates education and statistic in the history of professional education field, as it focuses on the context of Law 5.692 / 1971, which transformed secondary education in Brazil into a professional one. It aims to make analysis of the epistemological, theoretical, and methodological framework presented on the sources named Presidential Messages to the National Congress, analyzing some statistics of secondary education. The intention is to demonstrate the use of a discourse in which the numbers treated in a naturalized way serve as
\end{abstract}


tools to maintain social manipulation. The methodology used was literature review and document analysis. To understand the object of study, we ask: What is the relationship between epistemology and educational statistics? How high school education statistics are presented in Presidential Messages to the National Congress? In order to understand these aspects, we make use of concepts such as Gaston Bachelard's (1996) epistemological obstacle; René Rémond's (2003) political history, Pierre Chaunu (1976) and José D'Assunção Barros's (2004) Serial History. We also reflect on the construction of the history of science from a historical perspective, trying to understand the power relations based on authors such as Michel Foucault (2002), Thomas Kuhn (1987) and Gaston Bachelard (1996) The results obtained demonstrate that the use of educational statistics is presented in the studied sources in a way that the reader does not question the information, even if they diverge or demonstrate data that are different from reality, as there is a discourse built to difficult such inquiries.

Keywords: Educational statistics. High school teaching. Epistemological foundation. Presidential Messages to the National Congress.

\section{INTRODUÇÃO}

Podemos afirmar que a ciência é construída em contexto, por isso é importante que se compreenda a política, a economia e a sociedade em que se inscreve cada uma das concepções epistemológicas que envolvem o fenômeno científico. As diversas teorias epistemológicas importam para que a pesquisa científica, para que a ciência e sua epistemologia sejam entendidas, tendo em mente que cada teoria epistemológica requer métodos de pesquisas específicos e tem seu modo de compreender a produção do conhecimento e de perceber a construção da ciência.

Este estudo tem por objetivo fazer análise do referencial epistemológico, teórico e metodológico a partir da leitura das fontes nominadas Mensagens Presidenciais ao Congresso Nacional e sua apresentação das estatísticas do ensino de $2^{\circ}$ grau no Brasil. A intenção é demonstrar a utilização de um discurso em que os números tratados de maneira naturalizada servem como manutenção da ferramenta de manipulação social. À medida que se escolhe uma fundamentação epistemológica para trabalhar, também se está escolhendo uma forma de ver a ciência e de compreendê-la, tendo em mente que cada cientista que estuda as ciências como objeto de pesquisa tem seu modo particular de interpretá-las.

Neste sentido, este artigo se propõe a relacionar educação profissional e estatística, de maneira mais específica, estatísticas do ensino de $2^{\circ}$ grau. $O$ ensino de $2^{\circ}$ grau foi instituído pela Lei $n^{\circ} 5.692$ de 11 de agosto de 1971 , houve a fusão de todos os ramos do $2^{\circ}$ ciclo - o ensino normal, o ensino técnico industrial, o ensino técnico comercial e o ensino agrotécnico, se estabelecendo que todo o ensino médio da época fosse profissionalizante e de caráter terminal. A Lei $n^{\circ} 5.692 / 71$ perde sua vigência com a LDB de 1996. Tratamos 
aqui dos enlaces e relações guardadas entre o objeto de pesquisa supracitado e o referencial teórico e epistemológico que o embasará.

A metodologia utilizada foi a revisão bibliográfica que analisa autores diversos para elucidar tanto o nosso entendimento de ciência, a partir de uma perspectiva histórica e de poder, como o método de pesquisa, tendo por base o próprio método histórico e o método da história serial. Para tanto, fizemos uso de autores que discutem o conhecimento científico como Bachelard (1996; 1981), Kuhn (1987), Bourdieu (1989; 2003; 2004), Foucault (2002), entre outros.

Também desenvolvemos uma análise documental, tendo por base as Mensagens Presidenciais ao Congresso Nacional entre os anos de 1971, momento da criação da Lei no 5.692 e 1979, pois a partir de 1980 as fontes sofrem algumas alterações em suas temáticas e apresentações, o que nos levou a trabalhar com fontes que se mostram mais uniformes, até 1979. A partir de 1981 as fontes trazem alterações como mudança e/ou inclusão de temáticas anteriormente não tratadas, como por exemplo, a inclusão do subitem Políticas Trabalhistas. As Mensagens Presidenciais ao Congresso Nacional estão disponíveis no site da Universidade de Chicago denominado: Center for Research Libraries Global Resources Network.

O artigo está estruturado da seguinte forma: o texto introdutório apresentado na seção um; a seção dois discute a teoria epistemológica tendo por base os autores supracitados; a seção três reflete sobre os usos das estatísticas educacionais, fazendo uso dos métodos históricos e da história serial; por fim, as considerações finais são apresentadas na seção quatro.

\section{RELAÇÕES GUARDADAS ENTRE O REFERENCIAL EPISTEMOLÓGICO E AS ESTATÍSTICAS EDUCACIONAIS DO ENSINO DE 2 GRAU}

Refletir sobre a filosofia das ciências nos faz considerar que cada pesquisador compreende-a de uma maneira particular, entretanto, sempre devemos ponderar que a produção do conhecimento é algo não linear ou rígido, que a ciência tem rupturas e fluidez e sempre será resultado do momento histórico, político e social no qual está sendo construída.

Diante do exposto, evidenciamos o uso da epistemologia de Bachelard (1981), caracterizada por três elementos: o histórico; o racionalista; e o descontinuísta. O elemento histórico está presente porque o autor faz uso da história da ciência em sua fundamentação, assim como aprende com o materialismo histórico e em tudo que alicerça essa teoria epistemológica. $\mathrm{Na}$ sua visão, a história é recorrente, pois partindo das certezas do presente, descobre, no passado, as constituições progressivas da verdade. Para ele, à medida que o conhecimento evolui, existem retificações de determinados 
pensamentos, por consequência, a história retifica um erro de ontem. Ao estudar a epistemologia bachelardiana, Martins (2004, p. 18) diz que Bachelard entende "a verdade de hoje como uma retificação histórica de um erro de ontem. À medida que o conhecimento científico evolui, progride, pensamentos são retificados".

O segundo elemento da teoria de Bachelard é o racionalista, uma vez que se opõe à epistemologia empirista, contudo essa oposição não é o extremo oposto, pois rompe com a dicotomia empirismo versus racionalismo se colocando no meio termo. Contraria a ideia de que a simples observação dos fatos leve ao conhecimento, porquanto a prova científica se afirma na experiência e no raciocínio, no contato com a realidade e numa referência à razão. Já a noção descontinuísta diz respeito à ciência ser marcada por rupturas. Conforme explica Martins e Ferreira (2010a), para Bachelard, o conhecimento científico se aproxima sempre mais da verdade, mas nunca a alcança, corrigindo e retificando erros, num processo de natureza descontínua.

Bachelard (1978) considera o conhecimento como uma evolução do espírito, segundo ele, o espírito científico se constitui na destruição do espírito não científico. Essa tarefa é difícil, pois os erros se reforçam criando uma estrutura que deve ser rompida, superando os obstáculos. Lopes (1996) explica que, para Bachelard, o conhecimento científico se constrói pela retificação do erro, por isso, é necessário que existam erros na ciência para que ela se desenvolva. Conforme a autora, "[...] com Bachelard, o erro passa a assumir uma função positiva na gênese do saber e a própria questão da verdade se modifica" (LOPES, 1996, p. 252).

Neste contexto, entendemos ser importante deixar evidente o objeto de pesquisa e qual a sua relação com a teoria epistemológica que o embasa. Consequentemente, explanamos que as estatísticas são o ponto chave desse estudo, mais precisamente, as que tratam sobre o ensino de $2^{\circ}$ grau em nível nacional, cujo aparato legal é a Lei $n^{\circ} 5.692$ de 11 de agosto de 1971 . O ponto central é a discussão das estatísticas como um elemento não neutro, uma vez que partimos do pressuposto, conforme explica Jean-Louis Besson (1995), que elas não podem ser tratadas como realidade ou como verdadeiras ou falsas, devendo ser percebidas como um conhecimento relativo.

Ao expormos a ideia acima, podemos fazer uma relação da teoria epistemológica de Bachelard (1978) com o conhecimento estatístico, pois as estatísticas, no senso comum do meio científico, são tomadas ainda hoje como algo inquestionável, como um fator de verdade que não se discute, uma vez que se concebe que os números não mentem. Conceição (2008), após avaliar inúmeros artigos que derivaram de pesquisas da área da ciência médica, explica que numerosos trabalhos científicos são publicados anualmente e, dentre estes, a maioria usa as estatísticas para referendar as suas conclusões. $\mathrm{O}$ autor evidencia que, ao analisar esses estudos, constatou um "excessivo peso dado aos cálculos estatísticos como fatores definitivos, provas 
irrefutáveis, de conclusões discutíveis, quando não equivocadas". (CONCEIÇÃO, 2008, p. 397).

Os pesquisadores Abramov e Mourão Junior (2018) colocam que as estatísticas estão presentes da física aos estudos do mercado, contudo os pesquisadores, em geral, não demonstram compreender os mecanismos intrínsecos desse recurso, consequentemente, isso gera modos de pensar cientificamente equivocados. Os autores evidenciam que o meio científico é formado por pessoas e imaginários, portanto, sendo espaço de ação humana, é imbuído de um senso comum que, permeado por ideias inadequadas sobre as contribuições estatísticas para a ciência, tendem a tomar os resultados como verdades absolutas.

Conforme coloca Lopes (1996, p. 259),

[...] para Bachelard a ciência não capta ou captura o real, ela indica a direção e a organização intelectual, segundo as quais nos asseguramos que nos aproximamos do real. É no caminho do verdadeiro que o pensamento encontra o real; a realidade do mundo está sempre para ser retomada, sob responsabilidade da razão.

Ao tratarmos das estatísticas à luz da teoria bachelardiana, compreendemos essa visão empirista da ciência - na qual os dados estatísticos são tomados como verdadeiros - como um erro, um obstáculo científico, pois só a partir da observação dos fatos, numa perspectiva que considere a relação entre experiência e raciocínio, no contato com os caminhos da cientificidade, nos aproximaremos a cada instante mais da verdade. Segundo Martins e Ferreira (2010a, p. 5, grifo dos autores), "Os obstáculos epistemológicos não são apenas característicos da pré-ciência, mas "aderem aos conceitos" e perturbam mesmo o "novo espírito científico". São difíceis de serem desalojados e carregam valores afetivos que dificultam a objetivação".

Historicamente as estatísticas foram sistematizadas no século XX, mas a sua utilização vem de bem antes, entretanto, importa para nós não a sua utilização ao longo da história, mas do período a ser estudado. Compreendemos que já nas décadas de 1970 os sujeitos que faziam uso das estatísticas educacionais não as tomavam como uma representação da realidade, mas como a própria efetivação do real, e isso se evidencia nas publicações oficiais do governo, uma vez que divulgavam os índices estatísticos, entretanto, não os questionavam.

Ao falar sobre a ciência, Bachelard (1996) elucida que essa não é uma atividade simples e que os obstáculos epistemológicos necessitam ser enfrentados. A ciência deve considerar o momento histórico de sua época, levando, dessa maneira, a história da ciência a ser constantemente refeita pelo 
momento histórico em que vive a sociedade. Outro ponto importante na epistemologia bachelardiana é que a compreensão do conhecimento científico ocorre por meio das rupturas. O processo de desenvolvimento da ciência, por ser descontínuo, assume a existência das rupturas.

É nesse processo de ruptura e tentativa da superação dos obstáculos epistemológicos que acontece a produção do conhecimento científico, permitindo, assim, o progresso do conhecimento da ciência. De acordo com Martins e Ferreira (2010a), para Bachelard o avanço da ciência se dá contra um conhecimento anterior, negando-o; contudo, o não nunca é definitivo, permitindo, dessa forma, alargar o conhecimento anterior e retomá-lo sob nova ótica.

Outro cientista que, do mesmo modo, fundamenta a sua epistemologia numa perspectiva histórica e de rupturas é Thomas Kuhn (1987). Esse autor também defende que a ciência não se desenvolve de maneira linear, contínua e acumulativa. É importante esclarecer que apesar das aproximações entre esses dois estudiosos, a epistemologia de Bachelard se fundamenta no erro e a de Kuhn no acerto, pois, para este, o cientista sempre trabalhará para confirmar o paradigma. Contudo, Kuhn, assim como Bachelard, também não acredita na neutralidade da ciência. Ele chama de ciência normal a prática que visa:

"articular" o conjunto de teorias, modelos e representações compartilhados pelos cientistas e que constituem sua particular "visão de mundo". Esse conjunto de conhecimentos teóricos, equipamentos, técnicas, metodologias etc. compõe o que o autor chama de paradigma [...]. (FERREIRA; MARTINS, 2010b, p. 04, grifo dos autores).

Não trabalharemos com o conceito de paradigma do referido autor, entretanto se faz necessário dizer que Kuhn (1987) compreende que a ciência está sempre alicerçada no que ele denominou de paradigma. Conforme Kuhn (1987, p. 219), "um paradigma é aquilo que os membros de uma comunidade partilham e, inversamente, uma comunidade científica consiste em homens que partilham um paradigma".

O desenvolvimento científico ocorre por meio de rupturas, crises e revoluções. O paradigma se modifica diante de uma anomalia - pontos de aplicação problemáticas do paradigma - que podem gerar uma revolução científica e levar ao surgimento de um novo paradigma. Um paradigma se caracteriza pela aceitação da comunidade científica. Ferreira e Martins (2010b) explicam que a adesão a um paradigma, apesar de acontecer individualmente, é coletiva, pois necessariamente ocorre no seio da comunidade científica e é no interior dessas comunidades que acontecem as revoluções. De acordo com 
Kuhn (1987, p. 220), uma outra forma de compreender uma comunidade científica é perceber que ela "é formada pelos praticantes de uma especialidade científica". Assim, para o autor, dois elementos constituem uma comunidade científica: a especialidade sobre a qual se debruçam e o paradigma que partilham. Elementos que se desdobram em vários aspectos, tais como a presença de sujeitos que se inter-relacionam para a produção do conhecimento.

Aqui chamamos atenção para um outro aspecto convergente entre a teoria bachelardiana e a Kuhniana, a questão do coletivo. Bachelard coloca a existência da ciência de maneira socializada, tendo por base o controle social. Ferreira e Martins (2010a, p. 5-6) analisam que

[...] somente numa ciência socializada é possível realizar a psicanálise do conhecimento, dispor a série de erros. É também essa ciência socializada que permite padronizar os instrumentos de medida, e quantificar. Sob o olhar do "outro" é que se funda a objetividade, para Bachelard.

Ainda sobre esse aspecto coletivo da ciência, Kuhn (1987) chama a atenção para elementos que caracterizam uma comunidade científica como $o$ partilhar de uma mesma literatura, delimitando assim, a construção e a análise de objetos de pesquisa. Kuhn (1987, p. 211) elucida que "[...] A comunidade científica é um instrumento extremamente eficaz para maximizar o número e a precisão dos problemas resolvidos por intermédio da mudança de paradigma".

Para finalizar a questão epistemológica numa perspectiva da produção científica a partir de um viés histórico, social e coletivo também queremos destacar o estudioso Ludwig Fleck. O conhecimento, para Fleck, está "[...] ligado a pressupostos e condicionamentos sociais, históricos, antropológicos e culturais e, à medida que se processa, transforma a realidade" (DELIZOICOV, 2002, p. 56). Fleck, portanto, como os outros dois cientistas citados, não subtrai a neutralidade do sujeito, o que significa que este tem um papel ativo, fazendo com que sua visão da realidade socialmente transmitida seja introduzida ao conhecimento.

Neste sentido, queremos mais uma vez relacionar a teoria às estatísticas educacionais e deixar evidente a compreensão, igualmente como elucida Fleck, que a visão socialmente construída e transmitida pelos sujeitos é introduzida na ciência estatística. Historicamente se constata que tanto a análise como a divulgação dos dados estatísticos, na maioria das vezes, se dá de maneira a evitar questionamentos, o que ocorre, também, devido à não neutralidade dos cientistas e às marcas históricas e sociais construídas pelo coletivo. 
Martins (2016) destaca que o conhecimento para Fleck resulta de um processo histórico, social e coletivo, desse modo, os saberes carregam as marcas históricas e sociais do grupo que o constrói, destarte, o conhecimento é um produto social. A epistemologia fleckiana tem sua base em três polos: 0 sujeito, o objeto e o "estado do saber" de uma época e lugar específicos. Então, como em Bachelard e em Kuhn, podemos compreender que Fleck compreende a construção do conhecimento sob uma perspectiva histórica.

No que tange a visão coletiva da ciência, de acordo com Ferreira e Martins (2010b), o estudioso cunhou os conceitos de estilo de pensamento e coletivo do pensamento. $O$ primeiro conceito se refere a uma atitude e modo de agir e pensar de um grupo específico, e o segundo, diz respeito a um grupo ou comunidade de pessoas que partilham um estilo de pensamento. Cabe salientar que o estilo de pensamento sofre mutações ao longo da história, consequentemente, é o coletivo que confere ao indivíduo as regras e procedimentos imprescindíveis à observação. Delizoicov (2002, p. 56) evidencia:

Fleck entende que a disposição para o perceber orientado constitui o principal componente do estilo de pensamento (Fleck, 1986), que tem como raiz uma disposição para ver, observar ou perceber de forma dirigida, originária da tradição, formação e costume (Fleck, 1986). O coletivo de pensamento compartilha da atitude estilizada, de forma disciplinada [...].

Portanto, é o estilo de pensamento que define o que não pode ser pensado de maneira diferente. Neste sentido, temos grupos, comunidades, que se constituem historicamente por partilharem um mesmo estilo de pensamento, e uma determinada cultura. Por conseguinte, é necessário pensar os coletivos de pensamentos distintos, ou também podemos dizer, com uma diversidade de comunidades científicas, como é o caso da história da educação e a estatística, neste sentido, entendemos que a teoria dos campos do sociólogo Pierre Bourdieu (2004) é basilar para essa fundamentação epistemológica.

Bourdieu (2004) explica que o campo literário, o artístico ou científico são universos intermediários onde estão inseridos os agentes e as instituições que produzem a arte, a literatura e a ciência. O campo é um espaço com relativa autonomia, conforme elucida Bourdieu (2004, p. 21-22):

O campo científico é um mundo social e, como tal, faz imposições, solicitações etc., que são, no entanto, relativamente independentes das pressões do mundo social global que o envolve. De fato, as pressões externas, sejam de que natureza forem, só se exercem por intermédio do campo, são mediatizadas pela lógica do campo. 
Portanto, guardada as especificidades, podemos compreender que os outros campos, além do científico, até certo ponto, também seguem a mesma regra. O campo se define por estabelecer paradas em jogos, a estrutura do campo é um estado de relação de força. Para o autor, os campos são espaços de lutas simbólicas entre os agentes ou instituições que se envolvem na luta, está sempre em torno de um objeto de disputa desses ocupantes. O campo também monopoliza um capital específico que se fundamenta no poder ou na autoridade e tem interesses fundamentais em comum, conforme explica Bourdieu (2003).

Ao fazermos uso desse conceito, queremos compreender e estabelecer as relações de forças existentes que se constituíram entre as estatísticas e os discursos que se produziram em torno delas no que concerne às estatísticas do ensino de $2^{\circ}$ grau, entendendo que os vários campos envolvidos - o campo educacional, o campo burocrático, o campo econômico, o campo político e o campo científico (estatístico) - tinham interesses específicos que os conduziam. Segundo Bourdieu (2004, p. 22-23), "todo campo [...] é um campo de forças e um campo de lutas para conservar ou transformar esse campo de forças".

Para o autor, os agentes sociais desenvolvem estratégias que podem orientar tanto para a conservação como para a alteração das estruturas, elas também verificam, mesmo que de maneira genérica, que as pessoas que ocupam lugares favorecidos na estrutura tendem a conservar tanto a estrutura, quanto a sua posição. Compreendemos, assim, que os agentes ou instituições envolvidos nos diversos campos faziam uso do poder para utilizar as estatísticas do ensino de $2^{\circ}$ grau para gerir o mundo social. De acordo com Bourdieu (1989, p. 9):

O poder simbólico é um poder de construção da realidade que tende a estabelecer uma ordem gnoseológica: o sentido imediato do mundo (e, em particular, do mundo social) [...] uma concepção homogênea do tempo, do espaço, do número, da causa, que torna possível a concordância entre as inteligências.

Logo, podemos compreender que o poder simbólico dá coesão e coerência ao mundo social, pois constrói uma realidade homogênea impondo, dessa forma, sua dominação. Para tanto, o uso dos instrumentos do conhecimento, como é o caso das estatísticas, é empregado para construir essa realidade social. Bourdieu (1989) explica que as diferentes classes estão envolvidas numa luta simbólica e para se impor fazem uso desses instrumentos. 
Foucault (2002) coloca que, para conhecer realmente o conhecimento, se deve compreender quais são as relações de luta e de poder em que consiste o conhecimento. Como ao longo do texto evidenciamos que o conhecimento é um constructo histórico e social, não podemos deixar de refletir sobre esse aspecto, pois não existe uma epistemologia verdadeira, uma vez que o próprio desenvolvimento da ciência o desautoriza, conforme elucida Martins (2004).

Dessa maneira, Foucault (2002) explica que o conhecimento sempre será uma relação estratégica na qual o homem se encontra situado. De acordo com o autor "[...], é essa relação estratégica que vai definir o efeito de conhecimento e por isso seria totalmente contraditório imaginar um conhecimento que não fosse em sua natureza obrigatoriamente parcial, oblíquo, perspectivo. [...]" (FOUCAULT, 2002, p. 25). Esse caráter perspectivo do conhecimento não deriva do homem, mas do próprio conhecimento, do caráter polêmico e perspectivo que o conhecimento trás em si, e só é possível se falar dele, por que há batalha e o conhecimento é o efeito dessa luta.

A produção do conhecimento científico, em nossa perspectiva, não acontece sem estar envolvida por interesses e por lutas constantes que efetivam o poder de um campo ou instituições científicas. O conhecimento científico nunca será desinteressado, pois está diretamente relacionado às demandas econômicas e políticas que o norteiam, porquanto, como evidencia Stengers (2002), o cientista tira proveito da economia, da política, da técnica para fazer prevalecer a sua tese. Essa autora ratifica que a razão científica e a razão política estão associadas, pois a política não pode excluir as ciências, assim como, as ciências não são apolíticas.

Neste contexto, quando tratamos de um conhecimento político, Foucault (2002) coloca que, para realmente sabermos o que é o conhecimento, apreendê-lo em sua raiz, devemos nos aproximar dos políticos, devemos compreender quais são as relações de luta e poder existentes. Nesta perspectiva, é necessária a aproximação do campo político e burocrático para compreender as disputas em torno das estatísticas e da sua utilização. Questionamo-nos e procuramos entender as batalhas que foram traçadas em torno desse campo científico para gerir a realidade social e quais os encaminhamentos tomados, a partir dele, para a educação.

\section{AS ESTATÍSTICAS EDUCACIONAIS DO ENSINO DE 20 GRAU PELA LENTE DOS MÉTODOS HISTÓRICO E DA HISTÓRIA SERIAL}

O referencial teórico desse estudo tem por base a nova história política. Para Barros (2004, p. 106-107, grifo do autor), "o que autoriza classificar um trabalho historiográfico dentro da História Política é naturalmente o enfoque no "poder"." Esse crítico esclarece ainda que os objetos de estudo da história política são transpassados pela noção de poder. Esses elementos tanto podem 
ter um enfoque na história política tradicional como guerras e diplomacias, como também podem ser o modo de organização de unidades políticas como Estados e instituições, no viés da nova história política, de acordo com Barros (2004). No que concerne à teoria, Rusen (2010) explica que cabe a ela o papel de ser responsável por conceber o significado que constitui a organização científica do processo do conhecimento histórico, fazendo a preparação deste para a pesquisa.

Rémond (2003) afirma que o político é o espaço de gestão da sociedade global, ele conduz outras atividades e regulamenta seu exercício. As decisões da esfera política podem criar novas conjunturas que abrem campo para atividades de todo tipo, e isso ocorre porque ela se vincula a outros domínios da vida coletiva. Apesar de o autor considerar essa conjuntura, ele coloca que nem tudo é político, constatando "[...] que o político é o ponto para onde conflui a maioria das atividades e que recapitula os outros componentes do conjunto social." (RÉMOND, 2003, p. 447).

Cardoso (2012) observa que o poder político, para ser eficaz, deve interagir e aliar coerção a uma legitimidade, mesmo que pequena, mas que possibilite o funcionamento do sistema. Portanto, compreendemos que as estatísticas são um dos elementos usados para tal função. Segundo Cardoso (2012, p. 42):

O poder político é um sistema organizado de interações múltiplas cuja eficácia depende de aliar o monopólio da coerção à busca de uma legitimidade mínima, para garantir formas de participação que tornem possível tal sistema, e essa participação depende do êxito da socialização política (interiorização de normas que permitam o funcionamento dos mecanismos de regulação social no campo da política).

Neste sentido, a partir da interiorização e socialização das normas, nos propomos a investigar como se dava a sua divulgação no que se refere aos dados do ensino de $2^{\circ}$ grau. Para podermos analisar alguns desses aspectos, traremos exemplos das Mensagens Presidenciais ao congresso Nacional.

As Mensagens Presidenciais ao Congresso Nacional são anuais, se dividem em tópicos e estão organizadas, de maneira geral, da seguinte forma: Introdução; Política Econômico-financeira; Política Social; Política Externa; Justiça; e Forças Armadas. Dentro desses temas maiores, existem outros subtemas, como é o caso de Educação e Cultura, item que será analisado neste trabalho, inserido no tópico denominado Política Social. Constatamos que existem mudanças em relação aos tópicos principais entre os anos analisados, contudo, as temáticas tratadas nos documentos não sofrem modificações, são as mesmas. 
As análises aqui dispostas não têm a intenção de esgotar a questão da utilização das estatísticas educacionais e o seu uso na esfera política para garantir uma unidade na organização social. A intenção é demonstrar a utilização de um discurso, no qual os números tratados de maneira naturalizada servem como manutenção de ferramentas de manipulação social, sem questionamentos da divulgação de um determinado número, ou o porquê da escolha de uma determinada variável ao invés de outra. Como exemplo, podemos citar a Mensagem Presidencial de 1972, ao abordar a temática/variável das matrículas: "- no primário, 13.324 .510 matrículas em 1971, contra 12.812.029 em 1970. - no nível médio, 4.724 .675 matrículas em 1971, contra 4.083.586 em 1970. - no nível superior, 543.501 matrículas em 1971, contra 430.473 em 1970" (BRASIL, 1972, p. 59, grifo nosso) ou ainda a Mensagem Presidencial de 1979 ao informar:

Balanço dos principais indicadores sociais setoriais disponíveis permite aferir os progressos alcançados, entre 1973 e 1978: na educação, as matrículas no ensino de $1 .^{\circ}$ grau elevaram-se de 18,5 milhões para 21,5 milhões (aumento de $16 \%$; no segundo grau, o crescimento das matriculas foi de $79 \%$ (1,4 milhão em 1973 e 2,5 milhões estimados para 1978); [...]. (BRASIL, 1979, p. 131, grifo nosso).

Os números divulgados, nos dois exemplos acima, estão sem justificativas ou explicações, estão dados de maneira naturalizada nas duas fontes. Existem divergências entre os números divulgados na Mensagem Presidencial de 1972 e na de 1979, observe. Enquanto em 1971, o número de matrículas apontado pelo documento fica em torno dos quatro milhões e setecentos mil, no ano de 1973, dois anos depois, o número de matriculados foi de um milhão e quatrocentos mil, havendo uma queda no quantitativo geral.

Podemos aqui fazer diversos questionamentos: os dados de 1972 são falsos? Esses três milhões de alunos existiam e deixaram de se matricular? Se esse foi o caso, qual o motivo dessa queda no número de matrículas? Outra questão que pode ser levantada é: por que o discurso no texto deixa transparecer que houve um aumento no número de alunos matriculados, quando, na verdade, as estatísticas demonstram o contrário? Qual a intenção do tema/variável ser abordado assim? Essas indagações não têm respostas fáceis, e no caso deste trabalho, estão postas como pontos de reflexão. Entretanto, podemos inferir algumas conclusões.

Em todas as Mensagens Presidenciais analisadas, a ênfase sempre é no aumento do número de matrículas, oposto aos percentuais acima apresentados. A naturalização dos números, nas estatísticas, impossibilita que na maioria das vezes, essas inconsistências sejam notadas. Esse movimento, de apenas apresentar ou divulgar os números em percentuais, não favorece 
uma visão crítica da realidade, uma vez que a ciência estatística é tomada como uma verdade quase que absoluta por se tratar de números.

Neste sentido, podemos concluir que esses movimentos em divulgar os números, muitas vezes de maneira espaçada, como no exemplo acima, favorece uma organização da trama social, mediante o uso de um saber, neste caso, da ciência estatística, para manipular o âmbito social e político. Segundo Cardoso (2012, p. 41), a relação de poder:

[...] não serve somente para reprimir, mas também para organizar a trama social mediante o uso de saberes, o que é de grande relevância, já que tal poder não é o atributo de alguém que o exerce, mas sim uma relação. Se as personagens em presença (indivíduos, grupos, partidos, homens políticos) nada tiverem a trocar, não poderão entrar em uma relação de poder, isto é, uma relação de força de que não é possível para qualquer das partes em presença retirarse, mas na qual ninguém pode estar totalmente privado, pois, se assim fosse, teríamos saído da esfera propriamente política.

Diante do exposto, podemos conjecturar que a trama social foi implantada no período, na utilização do saber estatístico e a sua relação com a educação, possibilitando construir uma realidade em que os governantes legitimassem seus governos e suas ações, assim como também dessem legitimidade às políticas educacionais implantadas no Brasil. Neste sentido, podemos apresentar dados referentes aos montantes investidos na educação do período da ditadura militar que teve, conforme aponta Saviani (2008), após a exclusão do princípio da vinculação orçamentária na Constituição de 1967, uma redução nos recursos de $7,60 \%$ em 1970, para 4,31\% em 1975, tendo um pequeno aumento em 1978 de 5,20\%. Entretanto, não é esse o discurso utilizado nas Mensagens Presidenciais. Como exemplo, podemos citar várias referências feitas nas fontes em análise:

Os dispêndios federais em Educação totalizaram Cr\$2.987 milhões, o que representa acréscimo de quase $20 \%$, em termos reais, relativamente a 1971". (BRASIL, 1973, p.18, grifo nosso).

Verificou-se que em projetos de alguns setores com elevada prioridade, como Educação, por exemplo, a atuação do Governo não poderia ser avaliada apenas pelo lado dos gastos de capital, uma vez que dispêndios relativos ao funcionamento do sistema de ensino, embora não classificados como gastos de capital, nos termos da Lei no 
4.320/64, respondem por substancial parcela dos gastos no Setor. (BRASIL, 1974, p.19, grifo nosso).

Quanto aos gastos públicos nos setores sociais, cabe referir a realização, em 1974-1978, pela União e pelos Estados, de dispêndios em valorização de recursos humanos (educação, saúde, saneamento, trabalho e treinamento Profissional) da ordem de $\mathrm{Cr} \$ 766$ bilhões (preços de 1978). Em educação e saúde, os dispêndios da União cresceram 106\% e 138\%, respectivamente, em termos reais, entre 1973 e 1978. (BRASIL, 1979, p.13, grifo nosso).

Os extratos apresentados acima não se referem diretamente ao ensino de $2^{\circ}$ grau, mas à educação como um todo. Essa é outra forma de manipulação de informações muito presente nas Mensagens Presidenciais e ocorre corriqueiramente. As fontes não especificam quanto foi para cada nível de ensinou ou simplesmente juntam o montante investido em educação e saúde, como demonstrado pelo extrato retirado da Mensagem Presidencial de 1979. Contudo, para além dessas induções, nossa intensão é verificar mais uma vez a manipulação das estatísticas educacionais por meio de um discurso em que se colocam as informações fazendo com que o leitor acredite sem questionar. Sob esse aspecto, observa-se a ênfase nos valores positivos das mensagens, utilizando vocabulário e expressões como "acréscimo", "elevada prioridade", "valorização de recursos humanos" que reforçam o apelo a dados numéricos positivos e corroboram o esforço do Estado quanto ao uso do recurso que representa, em todas as mensagens, "gastos públicos" ou "dispêndios". Dessa forma, o discurso constrói todo um campo positivo em torno da ideia de que, apesar de haver um enorme "gasto público", o governo investiu em recursos humanos e na sociedade (inclusos os setores de educação e saúde) de forma a aumentar os índices de matrícula e, portanto, de acesso da população a esses setores.

Ao contrário do que apurou Saviani (2008), as Mensagens Presidenciais não expõem queda nos investimentos para a educação, o discurso sempre enaltece investimentos maiores e que ocasionam, segundo se pode constatar nos extratos acima, um aumento real com esses gastos. Na Mensagem Presidencial de 1974, por exemplo, especificam-se os dispêndios com educação que "respondem por substancial parcela dos gastos no Setor" (BRASIL, 1974). Mas que substancial parcela seria essa e o seu valor não são apresentados.

Chartier (2002), ao apresentar a sua compreensão acerca de Estado, afirma que devido ao antagonismo que existe entre os grupos sociais dominantes, o equilíbrio de tensões deve se perpetuar de forma que o soberano consiga impor seu monopólio de dominação. Esse foi outro aspecto averiguado no decorrer das análises e que pode ser verificado nos extratos dos textos já referenciados neste trabalho. 
O discurso dos presidentes sempre estará se aludindo a melhorias, a partir de um olhar sobre o seu antecessor. Cada presidente e os discursos analisados vai se referir ao seu antecessor como sendo o seu período de governo aquele que fez maiores investimentos e que melhorou a educação. $O$ número de matrículas sempre será maior do que nos anos anteriores, bem como os investimentos também terão seu montante elevado. Essas são apenas duas temáticas de tantas outras que poderiam ter sido citadas neste artigo.

Ainda podemos citar as políticas de auxílio aos estudantes como mais uma variável usada para demonstrar esse movimento de manipulação de discurso, por exemplo, o Presidente Médici (1969-1974) evidencia, na Mensagem Presidencial de 1972, que os recursos destinados à assistência aos estudantes tiveram um acréscimo no ano de 1971 quando aplicou a soma de 20.024.979,00 cruzeiros contra 10.419.097,00 investidos em 1970. Aqui, a referência é ao seu próprio governo, que de um ano para o outro elevou os investimentos nas políticas públicas de auxílio aos estudantes. Os dados numéricos apresentados carregam a intencionalidade de evidenciar a positividade do próprio governo Médici ao longo dos seus mandatos.

Já a Mensagem Presidencial de 1976 relata que foram empregados 300 milhões de cruzeiros para o ensino de $2^{\circ}$ grau. Enquanto que na mensagem de 1977 sobre assistência estudantil, informa-se que aplicou-se nos diversos níveis de ensino "Cr\$ 86,7 milhões, que permitiram a concessão de 118 mil bolsas" (BRASIL, 1977, p. 165), contudo, a mensagem não explicita qual o valor fornecido para cada nível das bolsas de estudo.

Considerando que as mensagens são apresentadas em diferentes momentos históricos, não há uma preocupação prévia aparente de que poderão ter os seus dados comparados, de forma, que os números são apresentados como verdades absolutas, não passíveis de questionamento.

Os valores apresentados se mostram bastante variáveis. Em 1971 a soma foi de 20.024.979,00, em 1976 foi de 300 milhões de cruzeiros aplicados apenas no ensino de $2^{\circ}$ grau e em 1977 apresenta-se uma queda para 86,7 milhões de cruzeiros. Não estamos aqui afirmando que esses valores não foram reais, mas que existe incoerência nas informações, pois se na Mensagem Presidencial de 1976, 300 milhões foram destinados apenas para o ensino de $2^{\circ}$ grau, por que na Mensagem Presidencial de 1977 esse número cai drasticamente? Nela é apontado um investimento total, em todos os níveis de ensino, de 86,7 milhões de cruzeiros e isso não é exposto pelo texto como um elemento preocupante ou de alerta. A apresentação do texto induz a uma leitura de que o investimento na educação, em especial, para assistência estudantil, continua a pleno vapor, como podemos verificar: 
Consciente de que os esforços que estão sendo dirigidos no sentido da expansão e melhoria do ensino não poderão prescindir de iniciativas de apoio ao estudante, como meio de instrumentalizar o que se pretende atingir, o Ministério da Educação e Cultura concebeu vários programas direcionados para esse objetivo. Quatro deles merecem especial relevo: o de bolsas de estudo para $01^{\circ}$ e $2^{\circ}$ graus, 0 de crédito educativo, a campanha de alimentação escolar e a do livro e material didático. O programa de bolsas de estudo aplicou nos diversos níveis de ensino, no decorrer de 1976, Cr\$86,7 milhões, que permitiram a concessão de 118 mil bolsas. (BRASIL, 1977. p. 165)

Como se pode constatar, a forma como o texto é apresentado constrói uma realidade que não dá margem para se conjecturar uma realidade na qual os investimentos vinham diminuindo, ao contrário, se lermos apenas esse extrato do documento, ficaremos condicionados a acreditar que os investimentos nas políticas públicas de auxílio estudantil tinham grande expressividade nos gastos do MEC.

Para finalizar a discussão sobre os conceitos é necessária a explicação da metodologia utilizada. Acerca do método histórico, Rusen (2015) afirma que este é a regulação do processo cognitivo e faz com que os procedimentos sejam reconstruíveis, controláveis e criticáveis. Para este autor, o pensamento histórico configura-se cientificamente, pois:

[...] consiste em um procedimento cognitivo que começa com
uma pergunta. Ele faz essa pergunta aos dados empíricos, nos
quais o passado está presente; obtém desses dados
informações sobre o que, onde, como e porque foi o caso no
passado. Em seguida, organiza essas informações em um
contexto de acontecimentos, que explica os acontecimentos
particulares em sua sequência temporal. O final desse
procedimento é aberto. Ele só se completa na representação
narrativa desse contexto temporal, em consequência da
pesquisa. (RUSEN, 2015, p. 171).

Destarte, o método histórico, guia a pesquisa por meio de regras que caracterizam o conhecimento histórico enquanto ciência. Outro método explorado denomina-se história serial, que tem por objetivo, de acordo com Barros (2004), o uso de fontes que demonstram uma certa homogeneidade ao mesmo tempo em que possibilitam quantificar ou serializar informações, na tentativa de detectar regularidades nos documentos analisados, como é o caso das Mensagens Presidenciais ao Congresso Nacional. Esse método também possibilita ao pesquisador analisar eventos ou dados e, apesar de estar intimamente ligado à história quantitativa, pode ser aplicado a objetos diversos 
como, por exemplo: História demográfica, história econômica e história das mentalidades.

No que concerne aos documentos que podem ser analisados na história serial, Barros (2004) ainda explica que uma grande diversidade de fontes pode ser serializada e entre elas estão as administrativas. $O$ autor elucida que:

A História Serial refere-se a ao uso de um determinado tipo de fontes (homogêneas, do mesmo tipo, referentes a um período coerente com o problema a ser examinado), e que permitam uma determinada forma de tratamento (a serialização de dados, a identificação de elementos ou ocorrências comuns que permitam a identificação de um padrão e, na contrapartida, uma atenção às diferenças, às vezes graduais, para se medir variações). (BARROS, 2004, p. 149).

Podemos afirmar que as fontes analisadas se enquadram nas exigências do método, são homogêneas. Observe-se que buscamos identificar os padrões e as diferenças presentes nas Mensagens Presidenciais acerca da educação e do ensino de $2^{\circ}$ grau estabelecendo relações entre elas. Barros (2004, p. 150) afirma que "a chave para definir uma prática como História Serial é, portanto, a busca de padrões recorrentes e variações ao longo de uma série de fontes ou materiais homogêneos. Mas não necessariamente a quantidade, ou pelo menos isso não é o principal."

Conforme explica Chaunu (1976, p. 52), "é necessário, à luz do serial, retomar aos pensamentos mais elaborados da elite. O serial leva a uma modalidade superior de análise da qualidade." Portanto, fica claro que o método serial possibilita ir além do caráter quantitativo, ao passo em que são analisadas recorrências e diferenças.

Diante do exposto, podemos afirmar que, ao nos utilizarmos dos números, tivemos a intenção de demonstrar como eles são empregados para compor um discurso capaz de manipular a realidade social, os números, as estatísticas educacionais foram importantes para chegarmos a essas constatações, pois, como afirma Desrosières (1995), os usuários das estatísticas nelas se apoiam para gerirem o mundo social, para tomarem decisões e fazer uso dos dados em debates.

\section{CONSIDERAÇÕES FINAIS}

Diante do que foi exposto neste ensaio, acreditamos deixar evidente que a fundamentação epistemológica que embasa esse estudo se relaciona com uma perspectiva histórica e de poder, bem como o referencial teórico- 
metodológico também segue a mesma perspectiva. O conhecimento científico, para ser produzido, está limitado a sua conjuntura histórica, está diretamente relacionado a um viés econômico e político que norteia as produções científicas.

Com as análises produzidas neste texto, podemos compreender que 0 cientista ocupa um lugar social, assim como a produção do conhecimento, e este lugar é marcado por interesses, ele é ideológico. Destarte, a estatística ocupa, na nossa pesquisa, esse espaço de interesses e lutas, esse lugar de poder, que considerado como uma verdade absoluta, referenda as tomadas de decisão do mundo social. Logo, compreendemos que a primeira questão que permeia esse estudo: Qual a relação entre a epistemologia e as estatísticas educacionais? Pode ser referenciada como esse lugar de fala e de disputas que, no caso das estatísticas são usadas para construir ou contribuir para a construção de um mundo social sob a perspectiva do poder hegemônico.

Já a segunda questão: Como as estatísticas do ensino de $2^{\circ}$ grau são apresentadas nas Mensagens Presidenciais ao Congresso Nacional? Evidenciamos que são apresentadas de maneira a criar um discurso que legitima uma forma de governo, são expostas de maneira que o leitor seja levado a acreditar em uma realidade inquestionável, ou pelo menos, de forma a dificultar a sua análise e contraste com estatísticas anteriores, reforçando os aspectos positivos de cada aspecto em relação aos dados apresentados por aquele governo quanto aos dados do governo (ou do ano) anterior. Todo o discurso se ampara na ideia de evidenciar os "esforços" governamentais na ampliação dos "gastos públicos", compreendidos na mensagem como as áreas de educação e saúde. Evidentemente, não há uma preocupação de justificar essas áreas como gastos, nem mesmo há uma preocupação em debruçar-se sobre dados de Mensagens Presidenciais emitidas anteriormente. Tanto é que os dados apresentados demonstram incoerência entre si quando postos em comparação.

Assim, compreendemos que, ao se utilizar das estatísticas educacionais nos documentos analisados, os governantes e quem os redige, usam estratégias que dificultam uma leitura real dos dados apresentados e se propõem a criar uma realidade de valorização de sua própria atuação.

\section{REFERÊNCIAS}

ABRAMOV, Dimitri Marques; MOURÃO JUNIOR, Carlos Alberto. A interpretação estatística como produção de verdades: reflexões éticas. Rev. bioét. (Impr.), v. 26, n. 4, p. 537-542, 2018. Disponível em: https://www.scielo.br/pdf/bioet/v26n4/1983-8042-bioet-26-04-0537.pdf. Acesso em: 08 de Julho 2020. 
BACHELARD, Gaston. A formação do espírito científico. Rio de Janeiro: Contraponto, 1996.

BACHELARD, Gaston. A epistemologia. Lisboa: Edições 70, 1981.

BACHELARD, Gaston. A Filosofia do Não. Coleção Os Pensadores. Tradução de Joaquim José Moura Ramos (et al.). São Paulo: Abril Cultural, 1978.

BARROS, José D'Assunção. O campo da história: especialidades e abordagens. Rio de Janeiro: Vozes, 2004.

BESSON, Jean-Louis. A ilusão das estatísticas. São Paulo: UNESP, 1995.

BOURDIEU, Pierre. Os usos sociais da ciência: por uma sociologia clínica do campo científico. São Paulo: Ed. da UNESP, 2004.

BOURDIEU, Pierre. Questões de sociologia. Tradução Miguel Serras Pereira. Lisboa: Fim de Século, 2003.

BOURDIEU, Pierre. O poder simbólico. Tradução de Fernando Tomaz. Lisboa: Difel, 1989.

BRASIL. Mensagem ao Congresso Nacional. Brasília, 1972, p. 104. Disponível em: http://ddsnext.crl.edu/. Acesso em: 11 de Julho 2020.

BRASIL. Mensagem ao Congresso Nacional. Brasília, 1973, p. 100. Disponível em: http://ddsnext.crl.edu/. Acesso em: 11 de Julho 2020.

BRASIL. Mensagem ao Congresso Nacional. Brasília, 1974, p. 237.

Disponível em: http://ddsnext.crl.edu/. Acesso em: 11 de Julho 2020.

BRASIL. Mensagem ao Congresso Nacional. Brasília, 1976, p. 202.

Disponível em: http://ddsnext.crl.edu/. Acesso em: 11 de Julho 2020.

BRASIL. Mensagem ao Congresso Nacional. Brasília, 1977, p. 281.

Disponível em: http://ddsnext.crl.edu/. Acesso em: 11 de Julho 2020.

BRASIL. Mensagem ao Congresso Nacional. Brasília, 1979, p. 244.

Disponível em: http://ddsnext.crl.edu/. Acesso em: 11 de Julho 2020.

CARDOSO, Ciro Flamarion. História e poder uma nova história política?. In: CARDOSO, Ciro Flamarion; VAINFAS, Ronaldo (Org.). Novos Domínios da História. Rio de Janeiro: Elsevier, 2012. p. 37-54.

CHARTIER, Roger. A história cultural: entre práticas e representações. Rio de Janeiro: DIFEL, 2002.

CHAUNU, Pierre. A economia: Ultrapassagem e prospectiva. In: LE GOFF, Jacques; NORA, Pierre (Org.). História: novas abordagens. Rio de Janeiro: Livraria Francisco Alves Editora S.A. 1976. p. 40-58.

CONCEIÇÃO, Mário José da. Leitura crítica dos dados estatísticos em trabalhos Científicos. Rev Bras Cir Cardiovasc, v. 23, n. 3, p. 396-399, 2008. 
Disponível em: https://www.scielo.br/pdf/rbccv/v23n3/v23n3a18.pdf. Acesso em: 09 de Julho 2020.

DELIZOICOV et al. Sociogênese do conhecimento e pesquisa em ensino: contribuições a partir do referencial Fleckiano. Caderno Brasileiro de Ensino de Física, v. 19, p. 50-66, mar. 2002. Número especial. Disponível em: https://periodicos.ufsc.br/index.php/fisica/article/view/10054/15384. Acesso em: 09 de Julho 2020.

DESROSIÈRES, Alain. Entre a ciência universal e as tradições nacionais. In: Besson, Jean-Louis (org.). A ilusão das estatísticas. Trad. Emir Sader. São Paulo: UNESP, 1995. p. 167-183.

FOUCAULT, Michel. A verdade e as formas jurídicas. $3^{\mathrm{a}}$ ed. Rio de Janeiro: NAU Editora, 2002.

FERREIRA, Juliana Mesquita Hidalgo; MARTINS, André Ferrer Pinto. Aula 13 A ciência em oposição ao senso comum. Disciplina História e Filosofia da Ciência. Natal: SEDIS/UFRN, 2010a.

FERREIRA, Juliana Mesquita Hidalgo; MARTINS, André Ferrer Pinto. Aula 11 Rupturas e Revoluções. Disciplina História e Filosofia da Ciência. Natal: SEDIS/UFRN, 2010b.

KUHN, Thomas S. A estrutura das revoluções científicas. $2^{\underline{a}}$ ed. Tradução de Beatriz Vianna Boeira e Nelson Boeira. São Paulo: Ed. Perspectiva, 1987.

LOPES, A. R. C. Bachelard, o filósofo da desilusão. Cad. Cat. Ens. Fis., v. 13, n3: p. 248-273, dez. 1996.

MARTINS, André Ferrer Pinto. Knowledge about Science in Science Education Research from the Perspective of Ludwik Fleck's Epistemology. Research in Science Education, v. 46, n. 4, p. 511-524, Agosto. 2016.

MARTINS, André Ferrer Pinto. Concepções de estudantes acerca do conceito de tempo: uma análise à luz da epistemologia de Gaston Bachelard. 2004. Tese (Doutorado em Educação) - Faculdade de Educação, Universidade de São Paulo, São Paulo, 2004.

RÉMOND, René. Por uma história política. 2. ed. Rio de Janeiro: Editora FGV, 2003.

RUSEN, Jorn. Teoria da História: uma teoria da história como ciência. Curitiba: Editora UFPR, 2015.

RUSEN, Jorn. Reconstrução do passado. Brasília: Editora Universidade de Brasília, 2010.

SAVIANI, Demerval. O legado educacional do regime militar. Cad. Cedes, Campinas, v. 28, n. 76, p. 291-312. 2008. Disponível em: https://www.scielo.br/pdf/ccedes/v28n76/a02v2876.pdf. Acesso em: 23 abril 2020. 
STENGERS, Isabelle. A invenção das ciências modernas. Tradução de Max Altman. São Paulo: Editora 34, 2002. 